initiatives already undertaken by the Clinton administration to streamline the part of the process under their own control. For example, the agency recently announced it would speed up the approval of experimental cancer drugs based on the model of "accelerated approval" it has used since 1991 for AIDS drugs. (Instead of relying on long-term studies that demonstrate clinical end points, such as prolonged survival, the FDA will base its licensing decisions on surrogate markers, such as tumor shrinkage, and will require confirmatory data after the drugs have reached the market.)

Aware that overseas approval of drugs not yet licensed here is a hot-button issue for agency critics (like "Nancy Sullivan"), the FDA intends to ask manufacturers of cancer drugs already approved in Europe and elsewhere to apply for special permission to allow "expanded" use of the drugs in this country before licensing. Although this "compassionate" use provision has long existed, the agency had not been aggressive in asking companies to take advantage of it.

Department of Health and Human Services Secretary Donna E. Shalala and Kessler deny that these recent proposals are a response to increasing pressures from the growing reform movement on Capitol Hill. The administration's work on these issues "started long before the current reform efforts" by Congress and was part of its own internal reform project, known as "Re-inventing Government," that has been headed by Vice President Al Gore, says Shalala.

Paradoxically, before Kessler took over FDA, the agency was riddled by a generic drug bribery scandal, low morale among career employees, and charges that it was too friendly with industry. Under Kessler, FDA has taken on major food companies for making false claims; overhauled food package labels; removed silicone gel breast implants from the market (with only a few exceptions); and, in its most ambitious undertaking, proposed a series of measures to restrict teenagers' access to cigarettes by regulating tobacco as a drug-containing substance (with nicotine being the drug) and cigarettes as drug-delivery systems, claiming to have the authority to do so under both its drug statutes and medical devices laws. The last move has particularly enflamed passionate responses on the part of some lawmakers, especially Thomas J. Bliley, Jr., a Republican from a tobacco-producing region of Virginia, and head of the House Commerce Committee, which is leading the reform efforts in that chamber of Congress.

The House bill is still in its earliest stages, but sponsors appear to have goals similar to those of the Senate's version. One of the more interesting provisions of the House bill is a section that would require that only one study demonstrate the efficacy of an experimental drug, rather than the several now required. House members spearheading the effort believe that these additional studies are "often redundant" and do nothing but slow down the process. The bill also provides for third-party reviewers (accredited by the FDA) and provisions that would make greater use of research data and approvals outside the United States. Also, it would try to hasten the approval of "offlabel" uses for many drugs.

It is still too early to assess the prospects of reform on Capitol Hill. Past attempts at the deregulation of health and safety agencies by this Congress have not been successful - in part because of voting coalitions of Democrats and defecting Republicans uneasy about tampering in this arena. Furthermore, President Clinton has stood solidly behind Kessler and the direction the FDA has taken under his stewardship. If Congress approves a measure that FDA supporters believe will seriously weaken the agency's ability to protect the public, the president will almost certainly veto it.

MARLENE CiMONS Washington, $D C$

\title{
Malaria drug import raises fears of resistance
}

Last month, under pressure from doctors and drug companies, the Indian government lifted a long-standing ban on the import of mefloquine, a potent antimalarial drug. Previously, mefloquine (manufactured by Hoffmann-La Roche) had been kept in reserve for use only in an emergency. Some public health experts believe the new policy is a mistake, and that it will rapidly lead to a major health crisis as the result of the emergence of resistant strains of malaria.

Until now, Indian officials have deliberately avoided using mefloquine. It is one of only two weapons available today (the other is halofantrine) against drug-resistant Plasmodium falciparum (PF), responsible for a severe form of malaria that affects the brain. Therefore, the previous policy was to introduce the drug only if existing drugs failed. Chloroquine, the antimalarial drug developed during World War II, is still the drug of choice in India; it is effective except in several "pockets" where malaria parasites have shown resistance. However, even in these places, health authorities are successfully treating patients with a second line of drugs including sulfonamides, primaquine and quinine.

Thus the decision to allow the unrestricted import of mefloquine when there is no real urgency is viewed with concern. Critics of the policy change fear that mefloquine's efficacy (it clears parasites in 48 hours) and ease of administration (a single dose is usually sufficient) will encourage its use in all cases of malaria, regardless of the parasite species. "This may lead to development of resistance to the last weapon we have," says V.P. Sharma, director of the malaria research center in New Delhi. "If this happens, India will become defenseless against malaria." Sharma estimates that unbridled use of mefloquine will render the drug "useless" in four years.

Gagan Singh Sonal, assistant director of the National Malaria Eradication Programme (NMEP), says his agency took a calculated risk in recommending the use of mefloquine. Sonal says the spurt in PF cases - one third of last years' 3 million malaria cases - and demand from the medical fraternity for mefloquine prompted the decision. However, according to Gagan, even though permission for its use has been given to private sector, the drug will not be used in the government's NMEP.

Attempting to allay fears of mefloquine abuse by patients or medical practitioners, Indian drug controller P.R. Dasgupta says the drug will be sold strictly by prescription, accompanied by a lab report confirming infection by chloroquine-resistant PF. Its use will be prohibited in $P$. vivax cases. Critics, however, are doubtful about the implementation of these regulations and allege that the government has succumbed to the drug lobby.

K.S. JAYARAMAN New Delhi, India 